www.jmscr.igmpublication.org

Impact Factor 5.244

Index Copernicus Value: 83.27

ISSN (e)-2347-176x ISSN (p) 2455-0450

crossref DOI: _https://dx.doi.org/10.18535/jmscr/v4i10.66

Journal Of Medical Science And Clinical Research

IGM Publication

An official Publication of IGM Publication

\title{
High Grade Asrtocytomas Whole Brain Radiotherapy (WBRT) vs Limited Volume Brain Radiotherapy (LVBRT)- A Prospective Randomized Study
}

\author{
Authors \\ Dr C.S.K. Prakash M.D (R.T) ${ }^{1}$, Dr Manne Srinivas, M.D (R.T) ${ }^{2}$ \\ ${ }^{1}$ Associate Professor, Department of Radiotherapy \& Oncology, Kakatiya Medical College and Mahatma \\ Gandhi Memorial Hospital, Warangal, India \\ ${ }^{2}$ Assistant Professor, Department of Radiotherapy \& Oncology, Rangaraya Medical College And \\ Government General Hospital, Kakinada, India \\ Corresponding Author
}

Dr Chennapragada Sri Krishna Prakash M.D (R.T)

H/O Dr N. Madhavi,Plot No 44, $3^{\text {rd }}$ Floor,Road No 4,

Mamatha Nagar, Old Nagole,Hyderabad-500 068.

Email: srikrishnaprakash@yahoo.co.in, csk_prakash@hotmail.com,PH:+91984800607

\section{ABSTRAC}

Purpose: To analyze the results obtained in patients with post operative High Grade Astrocytomas treated by adjuvant Radiotherapy.

Materials and Methods: The study was carried out between 1996 and 1999 at Kasturba Medical College and Hospital, Manipal 576 119. This is a prospective randomized study of 26 patients, who were randomized to Whole Brain Radiotherapy(WBRT) and Limited Volume Brain Radiotherapy (LVBRT) groups in postoperative

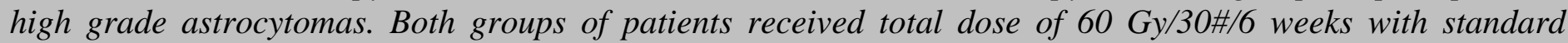
Radiotherapy technique based on pre and post operative CT scan reports and intraoperative findings.

The data was analysed for the prognostic factors like performance status, extent of surgery, grade of tumor. The radiation reactions (RTOG scale), survival patterns(for 6 months) were analysed.

Results: Majority (84.6\%) of the patients were males. Patients with Grade III histology had better survival than patients with grade IV( 90\%vs31.25\%) Patients with WBRT group developed more acute reactions than LVBRT group (Grade II reactions69 vs $23 \%$, grade III $23 \%$ vs 0). Patients treated for tumor volume $<4 \times 4 \mathrm{~cm} 2$ had better survival than with patients with $>4 x 4 \mathrm{~cm} 2$, up to $6 x 6 \mathrm{~cm} 2(62 \% \mathrm{vs} 29 \%)$. Patients underwent near total excision had better survival than those biopsy alone(100\% vs $10 \%)$. The overall survival was $61 \%$ vs $53 \%$ for WBRT vs LVBRT group. The observed test of significance was 0.546 and p values were $<0.1 \%$, which were not statistically significant.

Conclusion: Postoperative adjuvant Radiotherapy will provide better quality of life and survival benefit for the patients. The patients will not have a significant survival benefit whether treated by WBRT or by LVBRT. Hence, can be treated by LVBRT as there will be less toxicities. This study concepts were followed today with escalation of radiotherapy dose to the tumor and limiting dose to normal structures by latest and advanced techniques like Three Dimentional Conformal Therapy( 3D-CRT) or Intensity Modulated Radiotherapy (IMRT).

Key words: High grade gliomas , Whole Brain Irradiation vs Limited Volume Brain Irradiation. 


\section{Introduction}

The incidence of the primary intacranial and spinal axis tumors in India is $1.4 \%{ }^{1}$

The malignant gliomas account for 50-60 \% of intracranial neoplasms, Out of which Glioblastoma multiformae is the commonest. Eighty four percent of the malignant gliomas occur in supratentorial region and the remaining ones in infratentorial region. ${ }^{2}$ The presence of either vascular endothelial proliferation or a mitotic rate $>1$ per HPF is pathognomic of anaplastic changes ${ }^{3}$ but either feature is necessary for the diagnosis. Glioblastoma multiforme is distinguished from the other types by its variegated appearance; hence the term multiforme. Svien et $\mathrm{a} 1^{4}$ and kernohan et al ${ }^{5}$ used a four grade system designated as grade 1 to 4 that was patterned after the histological grading system for epithelial neoplasms used at the Mayo Clinic. ${ }^{5}$ Necrosis was used to divide the intermediate type astrocytoma from glioblastoma. ${ }^{6}$ Both systems based on the histological grade on the recognition of cellular anaplasia.

With the invention of CT \& MRI which drastically improved the ability to localize, diagnose and treat the patients with astrocytomas. CT \& MRI became the standard diagnostic imaging techniques and PET \& SPECT are used to distinguish neoplasia from radiation necrosis. ${ }^{7,8,9}$

Treatment modalities consist of surgery, radiotherapy and chemotherapy. Surgery is in the form of decompression+biopsy, partial, near total and total excision

Biopsy Can be performed either free hand or image directed as with stereotactic $\mathrm{CT}^{10,11}$.It is generally agreed that the tumor debulking can provide good initial palliation ${ }^{12}$. Reoperation reserved for small symptomatic and easily accessible tumors, largely as palliative procedure. ${ }^{13}$, 14,15

Randomized study comparing whole brain with treatment to the whole brain followed by a local boost to identical tumor doses has not delineated a survival difference. ${ }^{16}$ The optimal total dose is 55$60 \mathrm{~Gy}$ in doses of 1.7-2 Gy per fraction up to a dose of $60 \mathrm{~Gy} .{ }^{17}$ Radiation doses beyond $60 \mathrm{~Gy}$ to a larger target volume have not demonstrated any further survival benefit. The prospective clinical trial conducted by the Brain Tumor Study Group (B T C G 69-01) ${ }^{17}$ is the first clinical trail that proved that the post operative radiotherapy significantly increases the median survival time in patients with high grade gliomas when compared with neurosurgical treatment alone

The Scandinavian glioblastoma study group $(\mathrm{SGSG})^{18}$ also showed improvement in the median survival time as compared to those who received conservative management without radiotherapy or chemotherapy

Hochberg and Pruitt $^{19}$ found that $90 \%$ of recurrence occur within $2 \mathrm{~cm}$ of the primary site. Urtasun ${ }^{20}$ and all the recurrences were within their partial brain target volumes.

Marseyand Wallnes ${ }^{21}$ observed that Eight out of twlve recurrences were no more than $2 \mathrm{~cm}$ from the contrast enhancing margin of the first recurrence.

Choucair $^{22}$ et al reviewed 1047 patients with supratentorial GBM and anaplastic gliomas treated from 1976-1985. All these proved that the recurrence of tumor occurred within the margins of the original tumor.

A clinical trial by Ruth G.Ramsey and William.N. ${ }^{23}$ in a randomised study. This study concluded that a high dose delivered to a smaller volume resulted in a long survival time. Study by Hochberg and Pruitt Most of the tumor recurrences occurred within 1$2 \mathrm{~cm}$ of their tumor location. ${ }^{24,25}$

More over studies by Gasper and Fischer ${ }^{24}$ found that intracranial metastasis that develop after partial brain irradiation do not affect ultimate outcome as they are nearly always accompanied by relapse of the primary tumor.

RTOG/ECOG study ${ }^{25,26}$ in which no significance difference could be demonstrated between patients receiving 60dy vs $70 \mathrm{~Gy}$ to the tumor bed. A study by Miller et al" in 82 patients demonstrated no additional benefit with dosage $6 \mathrm{OGy}$.

In a series reported by Leibel ${ }^{27}$ proved better results with incomplete resection with EBRT than incomplete resection alone. 
Several clinical observations support the use of limited radiation portals, rather than whole brain irradiation. The majority of the malignant gliomas are unifocal at the time of initial presentation', less than $5 \%$ presented with multicentric lesions .

After initial treatment, most tumor reccurences occur at or within 1-2 cm of the original location ${ }^{25}$. Furthermore, 2nd tumor reccurence after resection of the reccurent lesion also occur most commonly at the primary tumor site.

An analysis between 1983 to 1988 of 70 patients with supratentorial malignant gliornas with pre and post operative CT scan, simulator films and CT scan films documenting tumor reccurence were analyzed, who were treated at London Regional Cancer Centre (LRCC) with whole skull R.T plus boost radiation therapy with the site of reccurence to the boost dose of radiation therapy. Recurrences outside boost were most common with inadequate boost margins, small boost volumes, temporal lobe tumors and ipsilateral wedge pair technique.

Irradiation dose not effect the ultimate outcome, because they are always accompanied by the relapse of the primary tumor.

Based on the above studies, this prospective randomized study was designed to know the acute, sub acute, sub acute and delayed adverse effects and survival benifits of Limited Volume Brain Irradiation (LVBRT) vs Whole Brain Irradiation in Malignant Astrocytomas.

\section{Materials and Methods}

This is a prospective randomized clinical trial, the study group being treated with external radiotherapy localized to the tumor with an appropriate margin depending on the pre operative CT Scan and intraoperative findings. The control group will be treated with whole skull plus boost external radiotherapy depending on CT Scan findings.

Pre Treatment Evaluation: The patients with confirmed histopathological diagnosis of high grade gliomas were evaluated by physical examination and with necessary laboratory investigations including complete hemogram, R.F.T. chest x-ray, C.T. Scan Brain (Plain \& contrast) and Magnetic Resonance Imaging [optional].

Once the patient is found eligible, as per criteria, an informed consent of the patient was obtained and included in the study/control groups after randomization.

\section{Inclusion Criteria}

1. Grade $3 \& 4$ gliomas,

2. Karnofsky's performance status $>60.2$. Age $<70$ years.

3. No previous history of radiotherapy or chemotherapy.

\section{Exclusion Criteria}

1. Multicentric foci of the disease $>3$ lesions.

2. Intaventricular \& brain stem gliomas.

The patients in both the groups received external radiotherapy from Tele Cobalt 60 or Linac [6MV photons] with or without electrons.

\section{Dose and Technique of Radiotherapy:}

A dose of 60 Gy in 30 \# over 5-6 Weeks was used in both whole skull irradiation and limited volume irradiation. The standard radiotherapy techniques of parallel opposed lateral field, ipsilateral wedge fields depending upon the target volume as identified by clinical, per operative, and imaging evaluation were applied.

The patient is placed in supine position and the head is immobilized with mould. The treatment plan will be optimized by, computerized treatment planning system, dosimeter information was reviewed by the Senior Radiation Oncologist \& physicist.

All the patients were given steroids and anti epileptics during the radiotherapy.

Treatment Volume: The patient in the limited volume Radiotherapy group was treated with a margin of $4 \mathrm{~cm}$ around the pre operative contrast enhancing lesion in the $\mathrm{C} \mathrm{T}$ scan or hyperdense margin on T2 weighted M R I scan. The field sizes ranged from $9 \times 9 \mathrm{~cm}^{2}$ to $12 \times 12 \mathrm{~cm}^{2}$ and with wedge fields $8 \times 8 \mathrm{~cm}^{2}$ to $11.5 \mathrm{x}$ I $1.5^{2}$

The other group was treated by whole brain radiation up to $46 \mathrm{~Gy}$ and followed by boost up to 
$60 \mathrm{~Gy}$ to the lesion of $4 \mathrm{~cm}$ margin with lateral parallel fields or wedge fields depending on the size of the tumor. The field size for whole skull radiotherapy groilp was ranged frown $13-14 \times 20 \mathrm{~cm}^{2}$.

\section{Post Treatment Evaluation}

1. Acute reactions during radiotherapy as per RTOG / EORT Scale.

2. Sub acute reaction are noted at 2-6 months after completion of radiotherapy.

3. Late reactions were after 6months of radiotherapy.

4. The survival patterns at 6 months were studied.

\section{Results}

This study is conducted from February 97 to December 98 in which a total number of 26 patients were included. These patients were randomized into two groups. one group received whole skull radiation therapy while the other group received limited volume irradiation. The whole skull radiation was given as 46 grays to the whole skull later local radiation was given with a margin of $4 \mathrm{~cm}$ to the initial pre operative tumor volume. The group receiving local radiation received 60 grays to the pre operative tumor volume with a tumor margin of $4 \mathrm{~cm}$ by linear accelerator or by telecobalt 60 .

Out of 26 patients who were randomized male patients predominated in both groups with $11(84.6 \%)$ in each group as against two (15.38 \%) female patients in each.

The age of the patients ranged from 12years to 61 years the mean age being 40.4years. Out of these the maximum number of patients belonged to the age group between $30-60$ Years. 21 out of 26 patients belonged to this group.

The symptoms with which the patients presented varied widely the commonest being headache and vomiting present in as much as nineteen out of twenty six patients. This was followed by seizures in the order of frequency which was present in six patients. Other less common symptoms like paresis, memory changes, speech difficulties, personality changes, syncope, visual and sensory changes. (table no 1).

The tumor was located commonly in frontal region in about 11 patients. In five other patients it was located in temporoparietal region. Few tumors were located in frontoparietal, frontotemporal, parietooccipital, and temporal regions (table 2).

The size of the tumor ranged between $3 \times 3 \mathrm{~cm} 2$ to $7 \times 7 \mathrm{~cm} 2$. But most of the tumors belong to $4 \times 4$ $\mathrm{cm} 2-6 \times 6 \mathrm{~cm} 2$ group (21/26). Blood group A was predominant in both groups.13/26 belong to this group, out of which $7(53.85 \%)$ belong to whole skull Radiotherapy group and six (46.15\%) belong to Limited volume irradiation group. These patients first subjected to surgery in the form of biopsy, partial excision or near total excision. In patients who underwent WSEBRT, biopsy in four (30.77\%), partial excision in three $(23.08 \%)$, and near total excision in six $(46.15 \%)$ patients. In patients who underwent LVRT, six (46.15\%) underwent biopsy, patial excision in five $(38.46 \%)$ and near total excision in two $(15.38 \%)$ patients (table 2).

Histopathology was carried out by the senior pathologist at Kasturba Hospital, Manipal and also by the pathologist at NIMHANS, Banglore. In patients who had WSEBRT, 7/13 (53.85\%) were of grade III and 6/13(46.15\%) were grade IV. Whereas in LVEBRT group, 3/13(23.08\%) were grade III and 10/13(76.92\%) were grade IV(table 2). In both groups, none of the patients experienced interruption of the treatments.

The patients were observed for reactions and haematological status as per Radiation Therapy Oncology Group (RTOG) scale for six weeks. Weekly patient review was carried out by the senoir radiation oncologist and the physicist about the field size, treatment set up, dosimetric caliculations, patient 's on mechine set up.

\section{a) Skin Reactions}

The reactions were classified as acute and graded. In WSEBRT group, Grade 1 reactions were experienced in $7.69 \%$, grade 2 in $69.23 \%$ and grade 3 in $23.07 \%$. In LVRT group, $61.54 \%$ 
experienced grade 1 and $38.46 \%$ in grade 2 . None grade 3 . In both the groups, none experienced grade 4 reactions.

\section{b) Ear}

In WSRT group, 30.77\% had Grade 1 and $69.23 \%$ had grade 2 reactions. In LVRT group, $23.08 \%$ developed grade 1 and $30.77 \%$ grade 2 reactions . These reactions resolved within one month after radiotherapy with symptomatic treatment.

\section{c) Haematological}

None of the patients experienced, fall of $\mathrm{Hb}<8$ gm\%, Twbc $<3600 / \mathrm{mm} 3$ and platelet count less than 1lakh during entire course of treatment.

Acute CNS reactions like changes in level of consciousness, worsening of neurological signs and generalized seizures did not occur in both groups of patients. All the patients were on prophylactic corticosteroids and anti epileptics. The corticosteroid dose was tapered after completion of EBRT.

Fifty to sixty percent of patients in both groups had nausea after radiotherapy, which was relived by anti emitics.

The head ache, occurring during treatment was relived by increasing dose of corticosteroids.

ii. Early Delayed Effects: The effects observed from 2-6 months of radiotherapy as follows.

Somnolescence syndrome was observed during3Rd month of Radiotherapy in both groups of patients.
Ten out of thirteen $(79.93 \%)$ in WSRT and 7/13 $(53.85 \%)$ in LVRT group developed the same.

Patients in both groups did n't experience fatigue or exacerbation of focal neurological signs at 6 months follow up.

iii. Late Effects: The late effects were assed at 6 mo follow up and graded according to RTOG, EORTC grading system.

In WSRT group, 2/13 (15.38\%) were without head ache, lethargy or any CNS dysfunction (GRADE 0).Four out of thirteen (30.77\%) had grade 1 and 7/13 had Grade 2 effects.

In LVRT group, 8/13 (61.54\%) patients were without any late reactions (Grade 0), 4/13 $(30.77 \%)$ had grade 1 reactions, $1 / 13(7.69 \%)$ had grade2 late reactions.

None of the patients in both groups had grade $3 \& 4$ late effects.

Survival Patterns: Patients who were having better performance status were hiving better survival. patients who underwent near total or total excision had better survival than those with sub optimal surgery. Patients with grade III astrocytomas had better survival than those with grade IV astrocytomas (table3,4,5,6) and plotted Kaplan Meyer survival curve. The observed test of significance was 0.546 and the $\mathrm{p}$ value for both groups was <0.1, which were not statistically significant. 


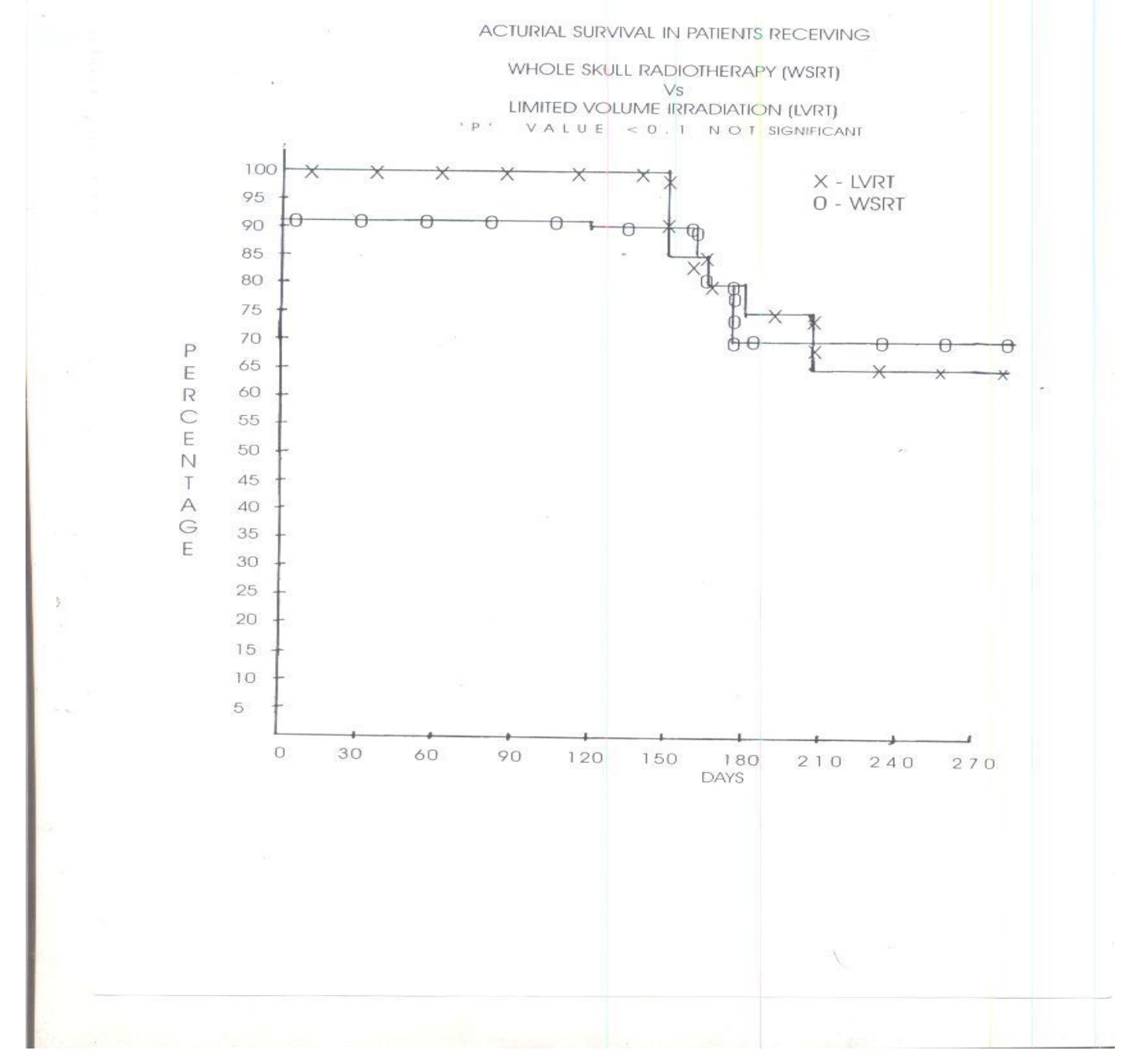

Table 1: Distribution of patients according to the sex, age, Karnofsky,s performance and symptoms at presentation of the patient

\begin{tabular}{|l|c|c|}
\hline Sex of the patient & Whole Skull Radio Therapy & Limited Volume Radio Therapy \\
\hline Male & $11(84.6 \%)$ & $1(84.6 \%)$ \\
\hline Female & $2(15.38 \%)$ & $2(15.38 \%)$ \\
\hline Age of the patient & Whole Skull RadioTherapy & Limited Volume Radio Therapy \\
\hline$<20$ Years & - & $1(7.69 \%)$ \\
\hline $20-40$ Years & $7(53.85 \%)$ & $5(38.46 \%)$ \\
\hline $40-60$ Years & $6(46.15 \%)$ & $6(46.15 \%)$ \\
\hline$>60$ Years & - & $1(7.69 \%)$ \\
\hline Karnofsky's performance status & Whole Skull RadioTherapy & Limited Volume Radio Therapy \\
\hline 60 & $2(15.38 \%)$ & $5(38.46 \%)$ \\
\hline 70 & $3(23.07 \%)$ & $1(7.69 \%)$ \\
\hline 80 & $1(7.69 \%)$ & $1(7.69 \%)$ \\
\hline 90 & $7(53.85 \%)$ & $6(46.15 \%)$ \\
\hline 100 & - & - \\
\hline $\begin{array}{l}\text { SYMPTOMS } \\
\text { PRESENTATION }\end{array}$ & & \\
\hline Headache \& Vomiting & Whole Skull RadioTherapy & Limited Volume Radio Therapy \\
\hline Other symptoms & $9(69.23 \%)$ & $10(76.92 \%)$ \\
\hline
\end{tabular}


Table 2: Distribution of patients according to site, size of thr tumor,blood group,and type of surgery

\begin{tabular}{|l|c|c|}
\hline & Whole Skull Radio Therapy & Limited Volume Radio Therapy \\
\hline Site of the tumor & & \\
\hline Frontal region & $5(38.46 \%)$ & $6(46.15 \%)$ \\
\hline Other sites & $8(61.54 \%)$ & $7(53.85 \%)$ \\
\hline Size of the tumor & - & \\
\hline$<4 \times 4 \mathrm{~cm}^{2}$ & $10(76.92 \%)$ & $1(7.69 \%)$ \\
\hline$>4 \times 4 \mathrm{~cm}^{2}-<6 \times 6 \mathrm{~cm}^{2}$ & $3(23.08 \%)$ & $11(84.6 \%)$ \\
\hline$>6 \times 6 \mathrm{~cm}^{2}$ & & $1(7.69 \%)$ \\
\hline Blood group & $7(53.85 \%)$ & $6(46.15 \%)$ \\
\hline A & $2(15.38 \%)$ & $3(23.07 \%)$ \\
\hline B & $1(7.69 \%)$ & $2(15.38 \%)$ \\
\hline AB & $3(23.07 \%)$ & $2(15.38 \%)$ \\
\hline O & & \\
\hline Type of surgery & $4(30.77 \%)$ & $6(46.15 \%)$ \\
\hline Biopsy & $3(23.07 \%)$ & $5(38.46 \%)$ \\
\hline Partial excision & $6(46.15 \%)$ & $2(15.38 \%)$ \\
\hline Near total excision & & \\
\hline Histopathology & $7(53.85 \%)$ & $3(23.07 \%)$ \\
\hline Grade III & $6(46.15 \%)$ & $10(76.92 \%)$ \\
\hline Grade IV & & \\
\hline
\end{tabular}

Table 3: Relation of survival rate with site and grade of the tumor

\begin{tabular}{|l|c|c|}
\hline FRONTALREGION & Whole Skull Radio Therapy & Limited Volume Radio Therapy \\
\hline TOTAL NO: OF PATIENTS & 5 & 6 \\
\hline GRADE III & 3 & 1 \\
\hline$>6$ MONTHS & $3(100 \%)$ & $1(100 \%)$ \\
\hline$<6$ MONTHS & - & - \\
\hline GRADE IV & 2 & 5 \\
\hline$>6$ MONTHS & $1(50 \%)$ & $2(40 \%)$ \\
\hline$<6$ MONTHS & I $(50 \%)$ & $3(60 \%)$ \\
\hline Location other than frontal region & & 7 \\
\hline TOTAL NO: OF PATIENTS & 8 & 2 \\
\hline GRADE III & 4 & $2(100 \%)$ \\
\hline$>6$ MONTHS & $3(75 \%)$ & - \\
\hline$<6$ MONTHS & $1(25 \%)$ & 5 \\
\hline GRADE IV & 4 & - \\
\hline$>6$ MONTHS & $2(50 \%)$ & $5(100 \%)$ \\
\hline$<6$ MONTHS & $2(50 \%)$ & \\
\hline
\end{tabular}

Table 4: Relation of survival rate with age and grade of the tumor

\begin{tabular}{|l|c|c|}
\hline Age & Whole Skull Radio Therapy & Limited Volume Radio Therapy \\
\hline$<20$ YEARS & - & 1 \\
\hline TOTAL NO: OF PATIENTS & - & 1 \\
\hline GRADE IV & - & $1(100 \%)$ \\
\hline$<6$ MONTHS & 7 & 5 \\
\hline 20-40 Years & 3 & 1 \\
\hline TOTAL NO: OF PATIENTS & $3(100 \%)$ & $1(100 \%)$ \\
\hline GRADE III & - & - \\
\hline$>6$ MONTHS & 4 & 4 \\
\hline$<6$ MONTHS & $2(50 \%)$ & $2(50 \%)$ \\
\hline GRADE IV & $2(50 \%)$ & $2(50 \%)$ \\
\hline$>6$ MONTHS & & 6 \\
\hline$<6$ MONTHS & 6 & 2 \\
\hline 40-60 Years & 4 & $2(100 \%)$ \\
\hline TOTAL NO: OF PATIENTS & $3(75 \%)$ & - \\
\hline GRADE III & $1(25 \%)$ & \\
\hline$>6$ MONTHS & & \\
\hline$<6$ MONTHS & & \\
\hline
\end{tabular}




\begin{tabular}{|l|c|c|}
\hline GRADE IV & 2 & 4 \\
\hline$>6$ MONTHS & $1(50 \%)$ & - \\
\hline$<6$ MONTHS & $1(50 \%)$ & $4(100 \%)$ \\
\hline $60-70$ years(grade IV) & - & 1 \\
\hline$<6$ MONTHS & - & $1(100 \%)$ \\
\hline
\end{tabular}

Table 5: Relation of survival rate with size and grade of the tumor

\begin{tabular}{|l|c|c|}
\hline$<4 \times 4 \mathrm{~cm}^{2}$ & Whole Skull Radio Therapy & Limited Volume Radio Therapy \\
\hline TOTAL NO: OF PATIENTS & - & 1 \\
\hline GRADE III & - & $1(100 \%)$ \\
\hline$>6$ MONTHS & & \\
\hline$<4 \times 4 \mathrm{~cm}^{2}-6 x 6 \mathrm{~cm}^{2}$ & 10 & 2 \\
\hline TOTAL NO: OF PATIENTS & 7 & $2(100 \%)$ \\
\hline GRADE III & $6(85 \%)$ & - \\
\hline$>6$ MONTHS & $1(15 \%)$ & 9 \\
\hline$<6$ MONTHS & 3 & $3(33.33 \%)$ \\
\hline GRADE IV & $2(66.66 \%)$ & $6(66.66 \%)$ \\
\hline$>6$ MONTHS & $1(33.33 \%)$ & \\
\hline$<6$ MONTHS & & 1 \\
\hline$>6 x 6 \mathrm{~cm}{ }^{2}$ & 3 & - \\
\hline TOTAL NO: OF PATIENTS & 3 & $1(100 \%)$ \\
\hline GRADE IV & $1(33.33 \%)$ & \\
\hline$>6$ MONTHS & $2(66.66 \%)$ & \\
\hline$<6$ MONTHS & & \\
\hline
\end{tabular}

Table 6: Relation of survival rate with type of surgery and grade of the tumor

\begin{tabular}{|l|c|c|}
\hline Biopsy alone & Whole Skull RadioTherapy & Limited Volume Radio Therapy \\
\hline TOTAL NO: OF PATIENTS & 4 & 6 \\
\hline GRADE III & 1 & - \\
\hline$>6$ MONTHS & $1(100 \%)$ & - \\
\hline$<6$ MONTHS & - & - \\
\hline GRADE IV & 3 & 6 \\
\hline$>6$ MONTHS & $1(33.33 \%)$ & - \\
\hline$<6$ MONTHS & $2(66.66 \%)$ & $6(100 \%)$ \\
\hline Partial excision & & 5 \\
\hline TOTAL NO: OF PATIENTS & 3 & 2 \\
\hline GRADE III & 1 & $2(100 \%)$ \\
\hline$>6$ MONTHS & $1(100 \%)$ & - \\
\hline$<6$ MONTHS & - & 3 \\
\hline GRADE IV & 2 & $1(33.33 \%)$ \\
\hline$>6$ MONTHS & $1(50 \%)$ & $2(66.66 \%)$ \\
\hline$<6$ MONTHS & $1(50 \%)$ & 2 \\
\hline Near total excision & & 1 \\
\hline TOTAL NO: OF PATIENTS & 6 & $1(100 \%)$ \\
\hline GRADE III & 5 & 1 \\
\hline$>6$ MONTHS & $5(100 \%)$ & $1(100 \%)$ \\
\hline GRADE IV & 1 & \\
\hline$>6$ MONTHS & $1(100 \%)$ & \\
\hline
\end{tabular}

\section{Discussion}

Brain tumor study group ${ }^{28}$ showed a significant increase in the survival period for patients treated with radiotherapy and $\mathrm{BCNU}$. Walker et $\mathrm{a} !^{17}$ in their randomized study proved that there is significant improvement in the median survival rate with post operative radiotherapy. Kristieins et at ${ }^{18}$ also proved role of post operative radiotherapy.
Before 1982 whole brain irradiation was considered as treatment for patients with high grade astrocytomas. Several clinical observations support the use of limited volume irradiation. In the study conducted by Hochberg, Pruitt, ${ }^{19}$ it was concluded that limited volume irradiation did not influence the outcome of these patients as the recurrences occur within $1-2 \mathrm{~cm}$ of the tumor after 
limited volume irradiation and outcome is same whether treated with wholeskull irradiation or limited volume irradiation.Moreover by limiting the volume we can deliver more dose to the tumor itself and limit the radiation dose to the normal brain tissue.

Based on above studies a prospective randomized trial was designed to compare total skull irradiation vs limited volume irradiation.

In both groups male patients predominated over female patients and constituted $84.6 \%$ of the total patients. majority of the patients $(80.76 \%)$ are in the age group of

$30-60$ years with mean age of 40.4 years. There was only one patient with age less than 20 years. The mean age group was 56 years in study by Walker et al. ${ }^{17}$

The Karnofsky's Performance Status ranging from 60-90 and almost equally distributed in Whole Skull Radiotherapy and limited volume radiotherapy groups. and survivals are comparable in both the groups.

The most common symptom was headache and vomiting in the both the groups.Sixty nine percent in whole skull Radiotherapy and $76.92 \%$ in limited volume radiotherapy presented with these symptoms. A study by Adam $^{29}$ and C.H.Chang et $\mathrm{al}^{26}$ showed that $60.4 \%$ presented with tumors in the frontal lobe. We could not draw any correlation regarding seizures as presenting symptom and the prognosis which carries better prognosis as shown in the study by Leibel et al. $^{27}$

The common site of the tumor in these patients was frontal region with $42.31 \%$ in this study and $35.30 \%$ in the study by C.H.Chang et $\mathrm{al}^{26}$ and $45 \%$ in study by Adam et al. ${ }^{29}$

Patients with whole skull radiotherapy had more acute reactions than limited volume radiotherapy group. Sixtynine percent of patients in whole skull Radiotherapy developed grade II reactions while $46.15 \%$ in limited volume radiotherapy developed no reactions.only $30.77 \%$ of patients developed grade II reactions in limited volume radiotherapy group.These results are comparable to results in the study by Cantane et al. ${ }^{30}$ It is observed that patients with temporal lobe lesions and who were randomized to local skull Radiotherapy group developed middle ear reactions when compared to tumors at other sites.

Haematological reactions are comparable in both the groups and none of the patients developed grade II reactions.

Somnolence syndrome was observed in $79.93 \%$ of patients who received whole skull Radiotherapy when compared to $53.85 \%$ of patients who received localized skull Radiotherapy.

Fifty four percent of patients with whole skull Radiotherapy developed grade II late reactions when compared to $7.69 \%$ of patients in local skull Radiotherapy.

The survival patterns with relation to site and grade were studied. It varied with grade of the tumor. The tumor in the frontal region which were histologically grade III had better survival than grade IV tumors in both groups. Cent percent of patients having grade HI tumors survived for $>6$ months while patients with grade IV tumors, there was fifty percent survival in whole skull radiotherapy group and forty percent in limited volume radiotherapy. Though there is subtle difference in survival in both groups with grade IV tumors, there was correlation in survival in both groups on the whole. Similar results were seen in tumors located in sites other than frontal region.

The grade of the tumor was limiting factor when the survival was studied in relation to age.there were almost equal number of patients in 20-40 years and 40-60 years. The survival for $>6$ months was $66.66 \%$ in patients with age between $20-40$ years while the survival in the age group 40-60 years was $50 \%$. The survival was less than 6 months in patients with age more than 60 years.

The study by Adams showed that lesser the tumor size better the survival. There was a definite relationship between survival and size of the tumor, the survival being better with tumors of smaller size. Cent percent of the patients having tumor size $<4 \mathrm{x} 4 \mathrm{~cm}^{2}$ survived for $>6$ months. There was a difference of survival in limited volume irradiation and whole skull irradiation with the tumor size ranging from $>$ $4 \times 4 \mathrm{crn}^{2}-<6 \times 6 \mathrm{~cm}^{2}$ which was more significant with grade IV gliomas the results being better 
with whole skull radiotherapy in tumors with this grade. The overall survival for more than six months in tumors with this size was $62 \%$. Only $25 \%$ of the patients with tumor size $>6 \times 6 \mathrm{~cm}^{2}$ months survived for $>6$ months.

The relation of survival with surgery was evident, when more extensive surgery was done to clear the tumor, the survival was better.The survival patterns in patients receiving whole skull irradiation and limited volume irradiation postoperatively were comparable with similar results.A study by Leibel et $\mathrm{a}{ }^{27}$ showed that survival was better with more tumor clearance and radiotherapy than with biopsy and radiotherapy.In our study $10 \%$ of the patients treated with biopsy and radiotherapy survived for more than six months.The survival for the same period in patients who underwent partial resection and near total resection were $62.5 \%$ and $100 \%$ respectively.

A study by Mario Ammirati et $\mathrm{al}^{31}$ in patients with malignant astrocytomas showed a significant improvement in survival as well as functional status when more tumor clearance surgery was done.In this study $61 \%$ of patients who underwent gross total resection survived for more than nine months while $39 \%$ of patients who underwent subtotal resection survived for only six months.

But a study by Adam et al $^{29}$ showed no correlation between the extent of surgery and survival.

Patients presented with progression of symptoms during follow-up period and recurrence of tumor was confirmed by CT scan. These patients were advised repeat surgery but refused due to financial constraints. Two of these patients received whole skull irradiation and the other two received limited volume irradiation. All of the recurrences were with in the field of irradiation. These patterns of failure are compared with study by Adam et al. ${ }^{29}$

The difference in the survival in the study Adam S.G. et al when compared to our study is due to reexcision of tumor after detection which was lacking in our study as the patients refused the same due to financial constraints.

\section{Conclusion}

Mean age for high grade astrocytomas is 40.4 years, predominantly seen in males. commonest blood group was A and headache and vomiting are most commonest presenting symptoms. Better prognosis was seen in grade three gliomas and small sized tumors. Patients who underwent near total excision had better prognosis. There was statistically significant difference in patients receiving whole skull radiation and LVBRT .In modern era, Limited Volume brain irradiation for high grade gliomas is the standard treatment in the form of three Dimentional Conformal Therapy( 3D-CRT) or Intensity Modulated Radiotherapy (IMRT), where ever the facilities were available.

Acnowledgement: My teacher and guide Prof. M.S.Vidya sagar, Retired professor and HOD, Department of Radiotherapy \&oncology, Kasturba Medical College and Hospital, Manipal 576119. My wife DR.N.Madhavi, Professor of OBG, Kamineni Institute of Medical Sciences, Narketpally,Telangana state, india.

\section{References}

1. Dastur, D. K., Lalitha, V. S. : Pathological analysis of intracranial space occupying lesion in 100 cases. J. Neuro. Sci. 6:575, 1968.

2. Chakrabarthi D., Sankar S.K., Bagchi A.K. A study of incidence of neoplasm in Central Nervous System, Neurology India, 21:1, 32-36, 1973.

3. Fulling, K. H., Nelson J. S. Cerebral astrocytic neoplasms in adults: Contribution of histologic examination to the assessment of prognosis. Semin Diagn Pathol 1: 152-163, 1984.

4. Svien, H. J., Mabon. R. F., Kernohan, J. W., et al : Astrocytomas. Proc Staff Meet Mayo Clin 24 : 54-64, 1949.

Kernohan, J. W., Mabon, R. F., Svien, H. J., et al A simplified classification of gliomas. Proc Staff Meet Mayo Clin 24: 71-75, 1949. 
5. Nelson J.S., Tsukada, Y. Schoenfeld D. et al Necrosis as a prognostic criteria in the malignant supra tentorial, astrocytic gliomas. Cancer 52:550-554, 1983.

6. Chamberlain M.C.,Murovic J.A Levin V.A Absence of contrast enchancement on CTbrain scans of paitents with supratentorial malignant gliomas. Neurology 38:1371-1374,1988.

7. Kelly, P. J., Daumas-Duport, C. Kispert, D. D. et al Imaged based stereotactic serial biopsies in untreated intracranial glial neoplasms. J. Neurosurg 66:865-874, 1987.

8. Kelly P. J., Daumas - Duport C. Scheitauer b.w. et al Stereotactic histologic correlations of CT and MRI - difined abnormalities in patients with glial neoplasms. Mayo Clin Proc 62: 450-459, 1987.

9. Chandrasoma PT,Smith MM,Apuzzo MLJ:Steriotactic biopsy in the diagnosis of brain masses: Comparision of the results of biopsy and resected surgical specimen. Neurosurgery 24: 160-165,1989.

10. Greene GM, Hitchon PW, Schelper RL, et al : Diagnostic yield in CT - guided stereotactic biopsy of gliomas. J Neurosurg 71: 494-497, 1989.

11. Ciric I, Ammirati M,Vick N, et al:Supra tentoral gliomas: Surgical consideration of immediate post operative results. Gross total resection versus partial resection. Neurosurgery 21:21-26, 1987.

12. Pool JL: The management of recurrent gliomas : Clin Neurosurg 15 : 265-280, 1968.

13. Ray BS : Surgery for recurrent intracranial tumors. Cli. Neurosurgerry $10: 1-30$, 1964.

14. Ray BS : Surgery for recurrent intracranial tumors. Cli. Neurosurgerry $10: 1-30$, 1964.

15. Shapiro, W. R., Green S. B., Burger P.C. et al : Randomised trial of three chemotherapy regimens and two radiotherapy regimens in postoperative treatment of malignant gliomas. J. Neurosurg 71: 1-9, 1989.

16. Walker M. D., Green S.B. Byar D. P. et al : Randomised comparisions of Radiotherapy and nitrosureas for treatment of malignant gliomas after surgery. N. Eng. J. of Med 303 : 1323-1329, 1980.

17. Kristiansen K, Hagen S, Kollevold T, et al: Combined modality theraphy for operated astrocytomas grade $3 \& 4$. Confirmation of value of post operative radiation and lack of potentiation of bleomycin on survival time. A prospective multicentre trial of Scandinavian Glioblastoma Study Group. Cancer 47: 649-652. 1981.

18. Hochberg, F. H. and Pruitt, A. A. Asumption in Radiotherapy of gliomas. Neurology 30: 907-911, 1980.

19. Urtasun, R., Feldstein, M. L., Partington, J., Tansichuk. H et al . Radiation and nitroimidazoles in supratentorial high grade gliomas : A second clinical trial. Br. J. Cancer 46 : 101-108, 1982.

20. Massey, V. and Wallner, K.E. Patterns of second recurrence of malignant astrocytomas. Int. J. Radiat. Oncol. Biol. Phy. 19:395-398, 1990.

21. Choucair, A. K., Levin, V. A., Gutin, P. H. et al. Development of multiple lesions during radiation theraphy and chemotheraphy in patients with gliomas. J.Neurosurg. 65:654-658,1986.

22. Ruth G. Ramsey, and William N. Brand. Radiotherapy of glioblastoma multiforme J. Neurosurg. 39: 197-202, 1973.

23. Gaspar LE, Fisher BJ, MacDonald DR et al : Supratentorial malignant treatment. Int J Rad Oncol Biol Phy 24: 55-57, 1992.

24. Nelson DF, Curran WJ Jr Scott C et al: Hyperfractionated radiotherapy and bischloro ethyl nitrosurias in the treatment of malignant gliomas-possible advantage observed at $72 \mathrm{~Gy}$ on $1.2 \mathrm{~Gy}$ b. i. d. 
fractionations: Report of the Radiation Therapy Oncology Group nprotocol 8302. In J Radiat. Oncol. Biol. Phys. 25: 193207, 1993.

25. Chang CH,Horton J, Schoenfeld D,et al: Comparision of post operative radiotheraphy in multidisciplinary management of malignant gliomas. A joint RTOG and ECOG group study. Cancer:52:997-1007,1983.

26. Leibel S. A. Teletherapy methods and expectations, in Apuzzo MLJ (ed): Malignant cerebral gliomas. Park Ridge, IL. American Association of Neurological Surgeons, 1990. Pp 159-171.

27. Wallner K. E. Galicich J. H, Krol G, et al : Patterns of failure following treatment of glioblastpma multiforme and anaplastic astrocytoma. Int. J. Radiat. Oncol. Biol. Phys. 16: 1405-1409, 1989.

28. Adam S. Garden, Moshe H. Maor, W. K. Alfred Yung et al. Outcome of Patterns of failure following limited volume irradiation for malignant astrocytomas. Radiotherapu and Oncology, 20:99-110, 1991.

29. Catane R., Schwade, J.G., Yaarr, et al: Follow up neurological evalution in patients with small cell lung carcinoma treated with: prophylactic irradiation and chemotherapy. Int. J. Radiat. Oncal. Biol. Phys. 7:105-109,1981.

30. Mario Ammirati, Nicholas Vick, Youlian Liao, et al: Effect of the extent of surgical resection on survival and quality of life in patients with supratentorial glioblastomas and anaplastic astrocytomas. Neurosurg, 21: 201-206, 19878. 